\title{
Leptin Gene Protects Against Cold Stress in Antarctic Toothfish
}

\author{
Ying Wang ${ }^{1,2,37}$, Huamin Wang ${ }^{1,2,3 \dagger}$, Linghong Hu ${ }^{1,2,3}$ and Liangbiao Chen ${ }^{1,2,3 *}$ \\ ${ }^{1}$ International Research Center for Marine Biosciences, Ministry of Science and Technology, Shanghai Ocean University, \\ Shanghai, China, ${ }^{2}$ Key Laboratory of Exploration and Utilization of Aquatic Genetic Resources, Ministry of Education, \\ Shanghai Ocean University, Shanghai, China, ${ }^{3}$ Shanghai Collaborative Innovation for Aquatic Animal Genetics and Breeding, \\ Shanghai Ocean University, Shanghai, China
}

OPEN ACCESS

Edited by:

Vincenzo Parrino,

University of Messina, Italy

Reviewed by:

Kevin Bilyk,

Montclair State University,

United States

Tomomi Watanabe-Asaka,

Tohoku Medical and Pharmaceutical

University, Japan

*Correspondence:

Liangbiao Chen

Ibchen@shou.edu.cn

tThese authors have contributed equally to this work

Specialty section:

This article was submitted to

Aquatic Physiology,

a section of the journal

Frontiers in Physiology

Received: 13 July 2021

Accepted: 19 October 2021

Published: 15 December 2021

Citation:

Wang $Y$, Wang $H, H u L$ and Chen L (2021) Leptin Gene Protects

Against Cold Stress in Antarctic

Toothfish. Front. Physiol. 12:740806.

doi: 10.3389/fphys.2021.740806
Leptin is a cytokine-like peptide, predominantly biosynthesized in adipose tissue, which plays an important role in regulating food intake, energy balance and reproduction in mammals. However, how it may have been modified to enable life in the chronic cold is unclear. Here, we identified a leptin-a gene (lepa) in the cold-adapted and neutrally buoyant Antarctic toothfish Dissostichus mawsoni that encodes a polypeptide carrying four $\alpha$-helices and two cysteine residues forming in-chain disulfide bonds, structures shared by most vertebrate leptins. Quantitative RT-PCR confirmed that mRNA levels of the leptin-a gene of D. mawsoni (DM-lepa) were highest in muscle, followed by kidney and liver; detection levels were low in the gill, brain, intestine, and ovary tissues. Compared with leptin-a genes of fishes living in warmer waters, DM-lepa underwent rapid evolution and was subjected to positive selection. Over-expression of DM-lepa in the zebrafish cell line ZFL resulted in signal accumulation in the cytoplasm and significantly increased cell proliferation both at the normal culture temperature and under cold treatment. DM-lepa over-expression also reduced apoptosis under lowtemperature stress and activated the STAT3 signaling pathway, in turn upregulating the anti-apoptotic proteins bcl2/1, bcl2a, myca and mdm2 while downregulating the proapoptotic baxa, p53 and caspase-3. These results demonstrate that DM-lepa, through STAT3 signaling, plays a protective role in cold stress by preventing apoptotic damage. Our study reveals a new role of lepa in polar fish.

Keywords: leptin-a, positive selection, polar fish, STAT3 signaling, p53, Dissostichus mawsoni

\section{INTRODUCTION}

The obesity gene was first discovered on chromosome 6 in morbidly obese mice in 1994; the gene contains a 501-bp open reading frame (ORF) which encodes a polypeptide called leptin (Zhang et al., 1994). The leptin gene has subsequently proven to be highly conserved in other mammals, with similarities of up to $96 \%$ between rats and mice and $83 \%$ among rats, mice, and humans (Murakami and Shima, 1995; Sasaki et al., 1996; Konfortov et al., 1999). Studies on fish leptin were initiated more recently. In 2005, with reference to human and murine leptin, a leptin homolog was cloned in the Japanese pufferfish (Takifugu rubripes) via comparative genomics, promoting studies on ichthyic leptin (Kurokawa et al., 2005). However, the sequence similarity among bony fishes is relatively low. Further, fishes harbor multiple leptin homologs owing to gene duplication. For example, Japanese medaka (Oryzias latipes) harbors lep- $a$ and lep- $b$, which are located on chromosomes 6 and 23, respectively, (Kurokawa and Murashita, 2009). Sequence alignment has 
revealed that the sequence similarity between lep- $a$ and lep- $b$ in Japanese medaka is only $16.5 \%$. Similarly, zebrafish (Danio rerio) also have two homologous genes, lepa and lepb (Gorissen et al., 2009), and the amino acid sequence similarity between the two is also low at $24 \%$. The T. rubripes, Salvelinus alpinus (Arctic char), and Pelteobagrus fulvidraco genomes carry the leptin- $a$ gene but not leptin- $b$ (González et al., 2000; Kurokawa et al., 2005; Frøiland et al., 2010; Choi et al., 2014). In contrast, in Cyprinus carpio (common carp) and Salmo salar (Atlantic salmon), leptin- $a$ is duplicated (Huising et al., 2006; Rønnestad et al., 2010). This suggests that the functions of leptins in fish may be more complicated than in mammals.

Recent studies indicate that leptin genes undergo rapid evolution and are subject to positive selection in many animal clades, including seals (Hammond et al., 2005; Yu et al., 2011), cetaceans (Yu et al., 2011), pikas (Ochotona spp.; Yang et al., 2008, 2011), heterothermic bats (Yuan et al., 2011), and primates (Benner et al., 2002; Siltberg and Liberles, 2002; Gaucher et al., 2003; Berglund et al., 2005; Yang et al., 2011). These findings suggest that selection on leptin may be an important contribution to environmental adaptation. However, the question of whether the leptin gene of fishes living in extreme cold environments has also undergone evolutionary selection is of interests, but has been not reported.

Dissostichus mawsoni, belonging to the Antarctic notothenioids, has adapted to the extremely low temperature of the ocean surrounding Antarctica. It has extensive lipid (mostly triglyceride) deposits under the skin and in the musculature (Chen et al., 2019), compared to other fish species in the same depth of water. As leptin plays a central role in the regulation of lipid metabolism, we speculate that the leptin of D. mawsoni has undergone adaptive functional evolution, in addition to regulating fat deposition, it also plays an important role in cold temperature adaptation. Recent studies have shown that leptin can inhibit cell apoptosis by activating the STAT3 signaling pathway, leading to increased expression of anti-apoptotic genes and a decrease of pro-apoptotic gene expression (McGaffin et al., 2009). Furthermore, it has been shown in many cell types that STAT3 activation is associated with cell survival and proliferation (Kanda et al., 2004; Yu et al., 2014; Banerjee and Resat, 2016). There is also evidence that leptin exerts its anti-apoptotic effect by reducing the level of p53 (Toro et al., 2014). In this study, a leptin-a gene (lepa) from D. mawsoni was cloned and transfected to a fish-liver cell line. We revealed that D. mawsoni leptin-a provides cells with potent protection from the stresses of low-temperatures.

\section{MATERIALS AND METHODS}

\section{Cloning and Tissue Expression Analysis of the leptin-a Gene of $D$. mawsoni}

The fish specimens used in the present study were the same as those used in our previous study (Chen et al., 2019). Total RNA was extracted from the liver, using TRIzol (Invitrogen, Carlsbad, CA, United States), tested for purity via agarose gel electrophoresis, and spectrophotometrically quantified (NanoDrop2000, Thermo Fisher, CA, United States). One microgram of total RNA was reverse-transcribed into singlestranded cDNA, using the Prime Script RT Kit (Takara, Japan). Based on the cDNA library of D. mawsoni sequencing results previously obtained by our laboratory, primers lepaF/lepa $\mathrm{R}$ (Table 1) for cloning were designed by screening the sequence in comparison with its homologs. PCR was performed using rTaq polymerase (TaKaRa, Japan) according to the following protocol: $95^{\circ} \mathrm{C}$ for $5 \mathrm{~min}, 34$ cycles of $95^{\circ} \mathrm{C}$ for $30 \mathrm{~s}, 58^{\circ} \mathrm{C}$ for $30 \mathrm{~s}, 72^{\circ} \mathrm{C}$ for 30 s. For tissue expression analysis, a FastStart Universal SYBR Green Master Kit (Roche, Germany) and LightCycler 480 (Roche, Germany) were used for qPCR with $18 \mathrm{~S}$ as the reference gene (Lauth et al., 2002). The $18 \mathrm{~S}$ primer was as used in the previous study. Thermal cycling was performed using an initial denaturation step of $95^{\circ} \mathrm{C}$ for 3 min followed by 40 cycles of $95^{\circ} \mathrm{C}$ for $10 \mathrm{~s}$, annealing temperature for $20 \mathrm{~s}$, and $72^{\circ} \mathrm{C}$ for $20 \mathrm{~s}$. The relative tissue expression levels of lepa were calculated by the $2^{-\Delta \Delta \mathrm{Ct}}$ method. The primer sequences are shown in Table $\mathbf{1}$.

\section{Selective Pressure Analysis}

To test the selective pressure of the lepa gene of $D$. mawsoni, we compared its sequence with those six fish species (L. japonicus, L. maculatus, S. chuatsi, E. coioides, O. latipes, and D. rerio) from relatively warm waters (more than $10^{\circ} \mathrm{C}$ ). Sequences were aligned using MEGA 6 (Tamura et al., 2013), which generated the phylogenetic tree for lepa genes via the maximum-likelihood method. Two likelihood-ratio tests (LRTs) were performed by means of the branch and site models of codon evolution using the codeml program (Yang, 2007) from the PAML package (Yang, 1997). Significance $(P$ value $<0.05)$ of the compared LRTs was conducted by the chi2 program from the PAML package.

\section{Construction of DM-lepa Expression Vector}

For lepa over-expression, the CDS sequence of lepa was cloned into the constructed $\mathrm{pTol} 2$-actin-egfp plasmid (the promoter was $\beta$-actin from zebrafish) to produce pTol2-actin-lepa-egfp. Due to the lack of a specific lepa antibody, we also introduced the His-tag before the lepa termination codon to produce the LEPAHIS fusion protein. In this way, we could use commercial HIS antibodies to detect LEPA protein expression for convenience. The expression plasmids then were transferred into E. coli DH-5 $\alpha$ competent cells, plated on culture dish containing $100 \mu \mathrm{g} \cdot \mathrm{mL}^{-1}$ kanamycin (Sangon, Shanghai, China) and cultured in a $37^{\circ} \mathrm{C}$ incubator for $12 \mathrm{~h}$ before analysis via individual bacterial colony

TABLE 1 | Primers for D. mawsoni lepa cloning and tissue expression.

\begin{tabular}{|c|c|c|}
\hline Primer name & Primer sequence $\left(5^{\prime}-3^{\prime}\right)$ & Application \\
\hline lepaF & GGGTITGGAGAGAGGTGAG & Cloning \\
\hline lepaR & TGTGGCCAGCGACTTACATA & \\
\hline lepaqF & GATCGACCTTGAGACGCACT & qPCR \\
\hline lepaqR & TCTTGGGATGGTTGGTCAGC & \\
\hline $18 \mathrm{SqF}$ & GTTCGATTCCGGAGAGGGAG & Reference gene \\
\hline $18 \mathrm{SqR}$ & CCTTCCTTGGATGTGGTAGCC & \\
\hline
\end{tabular}


PCR. The positive clones obtained via sequencing underwent expansion culturing, and plasmids were extracted using a plasmid extraction kit (Promega, Wisconsin, United States) in accordance with the manufacturer's instructions and stored at $-20^{\circ} \mathrm{C}$ until use.

\section{Culture and Plasmid Transfection of the Zebrafish Liver Cells}

The commercially available zebrafish liver (ZFL) cell line (American Type Culture Collection, ATCC, VA, United States) was cultured in culture medium containing $89 \%$ DMEM/F$12,10 \% \mathrm{FBS}$, and $1 \%$ penicillin/streptomycin at $28^{\circ} \mathrm{C}$ and $5 \%$ $\mathrm{CO}_{2}$ (i.e., conditions for optimum growth). Lonza Nucleofector (Lonza, Germany) was used for transfection at $70-80 \%$ confluence. G418 was added to the transfected ZFL cells after expansion culturing to select for successfully transfected cells. The concentration of G418 for the first week was $1,000 \mathrm{mg} \cdot \mathrm{mL}^{-1}$ and $500 \mathrm{mg} \cdot \mathrm{mL}^{-1}$ thereafter; these were the concentrations at which most of the non-transfected cells died. The G418 was then discarded, and the successfully transfected cells highlighted with green fluorescence.

\section{Protein Expression and Subcellular Localization of DM-lepa in Zebrafish Liver Cells}

The screened ZFL cells were cultured under optimal growth conditions for $48-72 \mathrm{~h}$ and then mixed with RIPA Lysis and Extraction Buffer (Thermo, CA, United States) and $1 \mathrm{mmol} \cdot \mathrm{L}^{-1}$ PMSF for protein extraction. The protein concentration was measured using a BCA Kit (Thermo, CA, United States) in accordance with the manufacturer's instructions, and proteins (30 $\mu \mathrm{g}$ per sample) were separated via SDS-PAGE and electro-transferred to a polyvinylidene difluoride nitrocellulose membrane (Millipore, Germany). Antibodies used in the assays included commercial HIS primary antibody (1:1000, Abcam, United Kingdom), $\beta$-actin (1:5000, Hua An, Hangzhou, China), and goat anti-mouse secondary antibody (1:5000, Hua An, Hangzhou, China). The proteins were visualized by enhanced chemiluminescence detection reagents (Beyotime, China).

To identify the localization of these proteins, ZFL cells were cultured in 24-well microporous plates (Corning, NY, United States) and fixed using 4\% paraformaldehyde at ambient temperature for $30 \mathrm{~min}$. Cells were then washed twice with PBS and blocked with treating buffer $(0.1 \%$ Triton X-100, $1 \%$ BSA) for $30 \mathrm{~min}$. Thereafter, the cells were counterstained with $2 \mu \mathrm{g} \cdot \mathrm{mL}^{-1}$ of $4^{\prime}, 6$-diamidino-2-phenylindole (DAPI, Sigma, St. Louis, MO, United States) for $5 \mathrm{~min}$ and washed thrice with water for $5 \mathrm{~min}$ each time. An inverted fluorescence microscope (ZEISS, Germany) was used to examine the ZFL cells and to obtain photographs.

\section{Cell Viability Assays by Cell Counting Kit-8}

A Cell Counting Kit-8 (CCK-8, Beyotime, China) was used to measure cell proliferation according to the manufacturer's protocol. The over-expression lepa group and control group cells were inoculated into a 96-well plate (Corning, NY, United States), and $10 \mu \mathrm{L}$ CCK-8 reagent was added to each well at the time of harvest. After that, the cells were incubated at $28^{\circ} \mathrm{C}$ and $18^{\circ} \mathrm{C}$ for $0,24,48,72$, and $96 \mathrm{~h}$, respectively. The low treatment temperature $\left(18^{\circ} \mathrm{C}\right)$ refers to our previous research (Chen et al., 2017). At the indicated time points, the absorbance at $450 \mathrm{~nm}$ was measured to determine the cell viability using the microplate reader (Synergy H4 Hybrid Reader, BioTek, United States). The data are representative of three independent experiments in triplicate.

\section{ROS Detection by Flow Cytometry}

The generation of intracellular ROS was determined using a fluorescein-labeled dye, $2^{\prime}, 7^{\prime}$-dichlorofluorescein diacetate (DCFH-DA, Beyotime, China), following the manufacturer's protocol. Briefly, the DCFH-DA fluorescent probe was added to cells $\left(5 \times 10^{4}\right.$ cells $\left./ \mathrm{mL}\right)$ followed by incubation for $20 \mathrm{~min}$ at their respective temperatures. Finally, cells were washed by PBS and then analyzed by a BD Accuri C6 flow cytometer (BD Biosciences, United States). FlowJo software (FlowJo, Ashland, OR, United States) was used to analyze the data.

\section{Cell Apoptosis Analysis}

Hoechst/propidium iodide (PI) staining (Beyotime, China) was performed to assess the percentage of dead cells or late-stage apoptotic cells. Briefly, the over-expression lepa group and the control group cells were inoculated into a 24-well plate (Corning, NY, United States), then $1 \mathrm{~mL}$ of fresh growth medium was added to each well. Incubation of the cells proceeded at $28^{\circ} \mathrm{C}$ and $18^{\circ} \mathrm{C}$ until they reached $80-90 \%$ confluence, respectively. After that, PI $(1 \mu \mathrm{g} / \mathrm{mL})$ and Hoechst $(1 \mu \mathrm{g} / \mathrm{mL})$ was added to each well and incubation continued for $30 \mathrm{~min}$ at room temperature. All samples were observed and photographed with a Zeiss fluorescence microscope (Zeiss, Germany). The percentage of apoptotic cells was calculated using ImageJ software (National Institutes of Health, Bethesda, MD, United States).

\section{Western Blot Analysis of Signal-Transduction Proteins}

Total cellular proteins of each sample were separated by SDSPAGE electrophoresis, and western blots were conducted as our previous study described. After blocking, the membranes were overlaid with primary antibodies for cleaved caspase-3 (1:1000, Hua An, Hangzhou, China), STAT3 (1:1000, Hua An, Hangzhou, China), and p53 (1:2000, Hua An, Hangzhou, China) overnight at $4^{\circ} \mathrm{C}$, then incubated with secondary antibody at $37^{\circ} \mathrm{C}$ for $1 \mathrm{~h}$. Proteins were visualized by enhanced chemiluminescence detection reagents (Beyotime, China). The endogenous control used was $\beta$-actin.

\section{Analysis by qRT-PCR of Genes Involved in Signal-Transduction Pathway}

Total RNA was extracted from cells using TRIzol (Invitrogen, United States) reagent according to the manufacturer's instructions. The methods for RNA quantity, reverse transcription and real-time PCR were as mentioned above. 
Supplementary Table 1 presents the primer sets used. Relative expression levels were calculated using the $2^{-\Delta \Delta C T}$ method, with $\beta$-actin as the reference gene for normalization.

\section{Sequence Analysis of the DM-lepa Gene}

ORFfinder $^{1}$ was used to predict the ORFs and encoded amino acid sequence of DM-lepa. The NCBI BLASTP tool was used to search for the homologous gene sequences of leptin in different species, including Lateolabrax japonicus (Gene Bank accession number: AHI85768.1), Lateolabrax maculatus (Gene Bank accession number: QFQ51510.1), Siniperca chuatsi (Gene Bank accession number: AHH86062.1), Epinephelus coioides (Gene Bank accession number: AMR58943), O. latipes (Gene Bank accession number: NP_001098190.2), D. rerio (Gene Bank accession number: NP_001122048.1), and Homo sapiens (Gene Bank accession number: NP_000221.1). The conserved motifs of the LEPA protein were analyzed using $\mathrm{MEME}^{2}$. The online tool ProtParam ${ }^{3}$ by ExPASy was used to predict the molecular weight of the DM-LEPA protein, its theoretical isoelectric point, instability index, aliphatic index, and grand average of hydropathicity. The online tool SignalP $4.0^{4}$ was used to predict signal peptide sequences. The online tool TMHMM Server $2.0^{5}$ was used to predict the transmembrane domain. NetPhos 2.0 Server ${ }^{6}$ was used to predict the Ser, Thr, and Tyr phosphorylation sites. NetNGlyc 1.0 Server ${ }^{7}$ was used to predict glycosylation sites. The SWISS-MODEL server ${ }^{8}$ was used to analyze higher-order protein structure.

\section{Statistical Analyses}

GraphPad Prism 8 (GraphPad Software, United States) was used for statistical analyses. All experiments were performed at least in triplicate. All data were expressed as the mean \pm SD. Comparisons between two groups were performed using Student's $t$-test, and comparisons among multiple groups were performed using two-way ANOVA. $P<0.05$ were considered statistically significant. One asterisk, two asterisks and three asterisks indicate $<0.05, P<0.01$ and $P<0.001$, respectively.

\section{RESULTS}

\section{Identification and Molecular-Structure Analysis of the DM-lepa Gene}

The coding sequence of the leptin-a gene in D. mawsoni has a 501-bp ORF to encode 167 amino acid residues (Figure 1A). The initial 20 amino acid residues at its $\mathrm{N}$ terminus function as the signal peptide (Figure 1B). The relative molecular weight was determined to be at about $16 \mathrm{kDa}$, the theoretical isoelectric point

\footnotetext{
${ }^{1}$ https://www.ncbi.nlm.nih.gov/orffinder/

${ }^{2}$ http://alternate.meme-suite.org/tools/meme

${ }^{3}$ https://web.expasy.org/protparam/

${ }^{4}$ http://www.cbs.dtu.dk/services/SignalP/

${ }^{5}$ http://www.cbs.dtu.dk/services/TMHMM

${ }^{6}$ http://www.cbs.dtu.dk/Services/NetPhos

${ }^{7}$ http://www.cbs.dtu.dk/services/NetNGlyc

${ }^{8}$ https://swissmodel.expasy.org/interactive
}

at 6.73, the instability index at 51.50, the aliphatic index at 99.82 and the grand average of hydropathicity at -0.092 , suggesting a hydrophilic protein. Multiple sequence alignments indicated that lepa of D. mawsoni shared a similarity of $71.43 \%$ with human leptin, as well as 55.42, 56.02, 57.23, 58.43, 38.55, and $18.87 \%$ with L. japonicus, L. maculatus, S. chuatsi, E. coioides, O. latipes, and $D$. rerio, respectively, indicating a relatively low sequence similarity $(<60 \%)$ among the fish species, although two cysteine residues forming disulfide bonds were conserved in vertebrates (Figure 1B). Prediction of the 3D structure also illustrated the structural similarity among fish and higher vertebrates, all of which carried four $\alpha$-helices and irregular corners to form a hollow barrel structure (Figure 1C).

\section{Expression Patterns of the DM-lepa mRNA}

Levels of the DM-lepa mRNA were analyzed via quantitative RT-PCR, normalized relative to $18 \mathrm{~S}$ mRNA of D. mawsoni. Transcription of DM-lepa mRNA was highest in muscle and lowest in intestine tissues. The next highest levels were observed in kidney and liver while weak expression was found in gill, brain, and ovary (Figure 2).

\section{Analysis of Selective Pressure}

Test of positive selection for the DM-lepa gene was carried out using the codeml program in the PAML package with the maximum likelihood codon model. The phylogenetic tree was constructed by MEGA 6 using the maximum likelihood model (Figure 3). The PAML branch model calculated the LRT test statistics to be $2 \Delta \ell=18.359215, p=0.000018$, and $\mathrm{df}=1$ (Supplementary Table 2). The $\omega$ ratio for the DM-lepa branch $\left(\omega_{1}=1.71507\right)$ was significantly higher than the fish species from warmer waters $\left(\omega_{0}=0.27320\right)$. Furthermore, estimations of the PAML branch-site models identified 5 sites $(43 \mathrm{~N}, 96 \mathrm{~K}$, 103F, 108T, and 142R) under positive selection (Figure 3 and Supplementary Table 3), suggesting that DM-lepa underwent a rapid evolution.

\section{Over-Expression and Subcellular Localization of DM-lepa in Zebrafish Liver Cells}

Since the D. mawsoni population occupies extremely cold temperatures, temperature was expected to be the most influential factor in determining evolution of DM-lepa. We investigated in vitro the functions of DM-lepa, because of the difficulty of artificial breeding. Owing to the lack of a commercial antibody specific to DM-LEPA, we constructed the pTol2-lepa-His-egfp expression vector (Figure 4A) to help detect the counterparts of DM-LEPA from the total ZFL cell lysates using a commercial anti-His tag monoclonal antibody. We eliminated the stop codon and His tag in the expression vector (Figure 4B) and transfected ZFL cells (Figure 4C) to identify the subcellular localization of DM-LEPA. Western-blot analysis of the total protein in ZFL cells indicated that the molecular weight of the mature protein at $16.04 \mathrm{kDa}$ was consistent with predictions (Figure 4D). Detection of green fluorescent proteins 
A

1 ATGGACAACACTTTGGCGCTCCTGTTTCCTCTGCTGTTCATCTTCAGTGTGGCTACAGCT

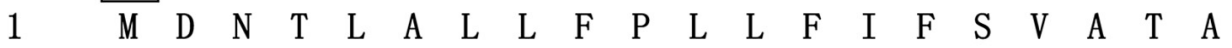

61 GCTCCTCTGCCAATGGACGTAGTAAACATGAAATCAACAGTTAAGCGGATTTCTGAAACG

$\begin{array}{lllllllllllllllllllll}21 & \text { A } & P & \text { L } & P & M & D & V & V & N & M & K & S & T & V & K & R & I & S & E & T\end{array}$

121 TTGGTGAACAGTCTGAACCAACACTTACAGGTGCAGGACGATTCTGGTCGGACGCTCAGT

$\begin{array}{llllllllllllllllllllll}41 & \text { L } & \text { V } & \text { N } & \text { S } & \text { L } & \text { N } & \text { Q } & \text { H } & \text { L } & \text { Q } & \text { V } & \text { Q } & \text { D } & \text { D } & \text { S } & \text { G } & \text { R } & \text { T } & \text { L } & \text { S }\end{array}$

181 CCACCTGCTGCTGATCTGAATGGACCTTCCTCCATAGTGATCGTCTTGGAGGGTTTTAAT

$\begin{array}{lllllllllllllllllllll}61 & \mathrm{P} & \mathrm{P} & \text { A } & \text { A } & \text { D } & \text { L } & \text { N } & \text { G } & \text { P } & \text { S } & \text { S } & \text { I } & \text { V } & \text { I } & \text { V } & \text { L } & \text { E } & \text { G } & \text { F } & \text { N }\end{array}$

241 CGCAAGATAAGTAGTGACTCCTACTTTGCGGTGAAGCAGACCAAGTGTCATATCTCTTCA

$\begin{array}{lllllllllllllllllllll}81 & \mathrm{R} & \mathrm{K} & \mathrm{I} & \mathrm{S} & \mathrm{S} & \mathrm{D} & \mathrm{S} & \mathrm{Y} & \mathrm{F} & \mathrm{A} & \mathrm{V} & \mathrm{K} & \mathrm{Q} & \mathrm{T} & \mathrm{K} & \mathrm{C} & \mathrm{H} & \mathrm{I} & \mathrm{S} & \mathrm{S}\end{array}$

301 CTGACGAGTTATGTCAGGGAGTGGATGAAGGCGCAATGCAGTGAGCAGCAGCCCAGAGGT

$\begin{array}{lllllllllllllllllllll}101 & \text { L } & \text { T } & \text { S } & \text { Y } & \text { V } & \text { R } & \text { E } & \text { W } & \text { M } & \text { K } & \text { A } & \text { Q } & \text { C } & \text { S } & \text { E } & \text { Q } & \text { Q } & \text { P } & \text { R } & \text { G }\end{array}$

361 TTAGAGCCAGCGTCGCTGCTACGGCTGAAACAGCGGAGTCGACCGGAGTTCTTGGACACT

$\begin{array}{lllllllllllllllllllll}121 & \mathrm{~L} & \mathrm{E} & \mathrm{P} & \mathrm{A} & \mathrm{S} & \mathrm{L} & \mathrm{L} & \mathrm{R} & \mathrm{L} & \mathrm{K} & \mathrm{Q} & \mathrm{R} & \mathrm{S} & \mathrm{R} & \mathrm{P} & \mathrm{E} & \mathrm{F} & \mathrm{L} & \mathrm{D} & \mathrm{T}\end{array}$

421 GTGAGCACCGAGGCTCTCATGAGAGTAAGGGAGTTCCTCAATCTGCTGCTACAAAACTTG

$\begin{array}{lllllllllllllllllllll}141 & \text { V } & \text { S } & \text { T } & \text { E } & \text { A } & \text { L } & \text { M } & \text { R } & \text { V } & \text { R } & \text { E } & \text { F } & \text { L } & \text { N } & \text { L } & \text { L } & \text { L } & \text { Q } & \text { N } & \text { L }\end{array}$

481 GATAATCTTGAATCTTGCTGA

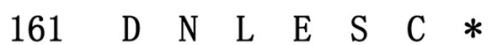

B

Signal peptide

Helix A

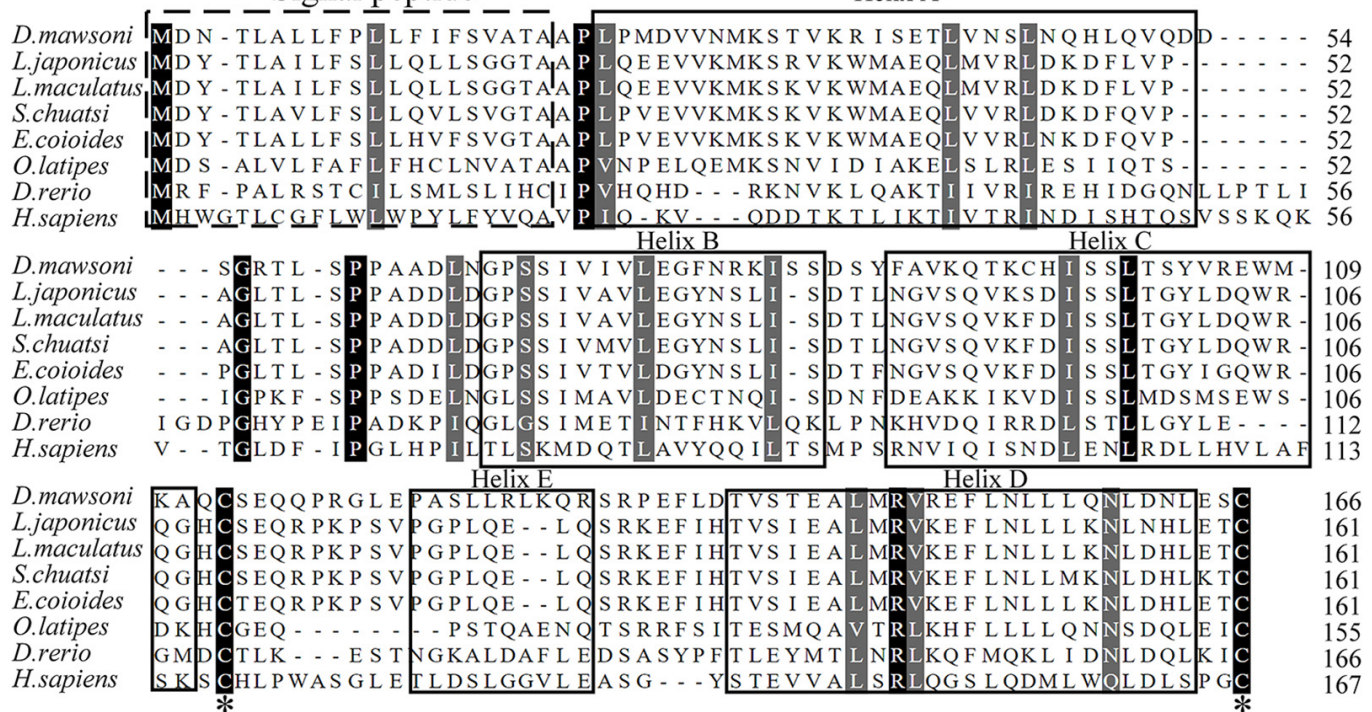

C
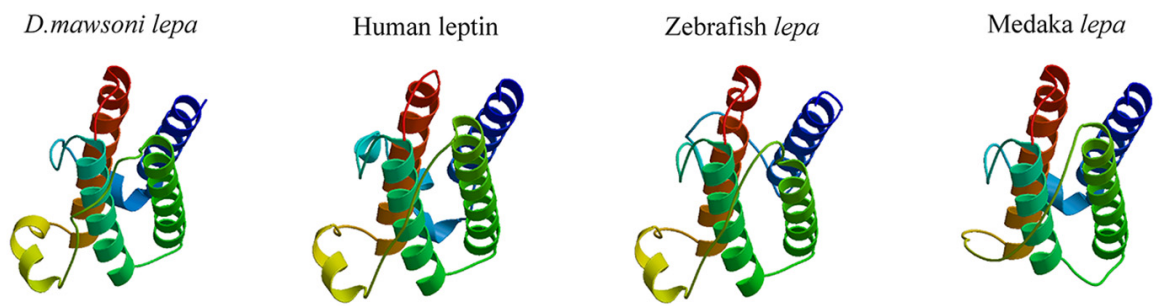

FIGURE 1 | Characterization of $D$. mawsoni lepa. (A) Coding sequence and encoded amino acid sequence. The box and the asterisk indicates the start codon, the stop codon, respectively. (B) Alignment of leptin-a homologs among the vertebrates. The signal peptide and conserved function domains are indicated with the boxes. Identical amino acid residues are shown in black and the amino acids with $>50 \%$ similarity shown in gray. Two asterisks indicate the conserved cysteine residues, which form a single disulfide bridge. (C) Predicted tertiary structure in different species. Four $\alpha$-helices are displayed in brown, blue, dark green, and green helices. 


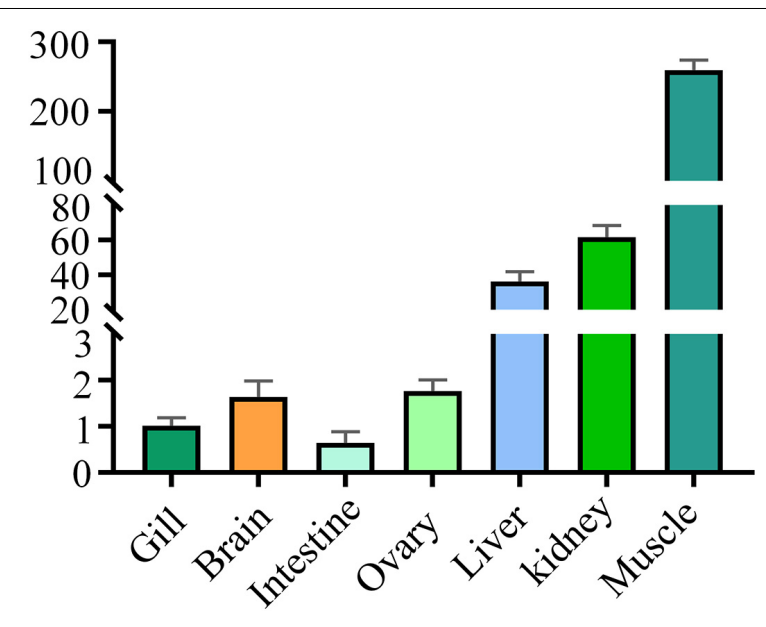

FIGURE 2 | Expression patterns of DM-lepa in different tissues. The $y$ axis indicates the relatively expression level with associated standard error bars, $n=3$ (biological replicates), ${ }^{\star \star} P<0.01,{ }^{\star \star *} P<0.001$.

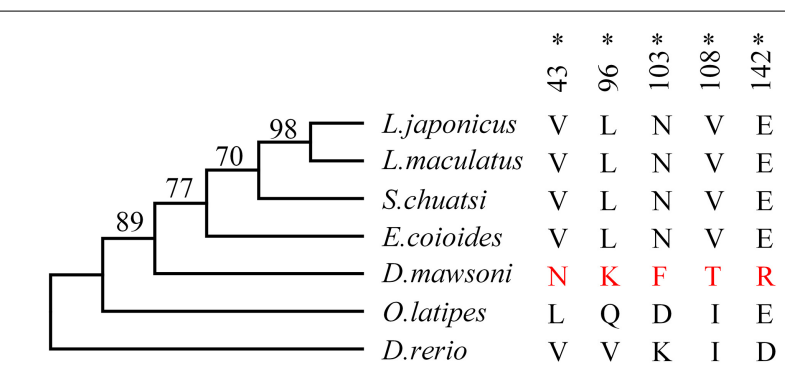

FIGURE 3 | Positive selection analysis. Numbers at the branches indicate the bootstrap support. Amino acids marked in red are positive selection sites for D. mawsoni, ${ }^{\star} P<0.05$.

indicated that the DM-LEPA protein was primarily localized in the cytoplasm rather than the nucleus (Figure 4E), a feature suggestive of a secretory protein.

\section{The Effect of Over-Expression of DM-lepa on Cell Apoptosis, Proliferation, and ROS Content}

It has been reported that leptin plays an important role in the regulation of cell proliferation and apoptosis (McGaffin et al., 2009; Lam et al., 2010). Accordingly, we determined the cell proliferation and apoptotic index of the DM-lepa over-expression group under normal culture temperature $\left(28^{\circ} \mathrm{C}\right)$ and cold conditions $\left(18^{\circ} \mathrm{C}\right)$. By using CCK- 8 assay, we observed that overexpression of DM-lepa significantly increased cell proliferation at either normal or cold temperatures (Figures 5A,B). By contrast, the control cells proliferated relatively slowly (Figures $5 \mathbf{A}, \mathbf{B}$ ). No significant difference in apoptotic signals was detected between the control and DM-lepa cell groups at $28^{\circ} \mathrm{C}$ (Figure 5C). However, after cold treatment at $18^{\circ} \mathrm{C}$ for 5 days, a considerable proportion of apoptotic cells was observed in the control, but a significantly lower proportion of apoptosis was detected in DM-LEPA cells (Figure 5C). Approximately 28\% of cells exhibited apoptosis in the DM-lepa over-expression group, compared with $67 \%$ in the control (Figure 5D). Meanwhile, the key protein levels of caspase-3 in DM-lepa over-expression cells were also lower than in the control group during apoptosis under cold temperature, as evaluated by western blotting (Figure 5E). A recent study shows that leptin can modulate ROS generation and thus control cell apoptosis (BlanquerRosselló et al., 2015; Hu et al., 2019). Our investigation of ROS generation indicated that over-expression of DM-lepa had no effect on the intracellular level of ROS at the normal culture temperature, while significantly decreasing ROS generation under cold treatment (Figures 5F,G); this demonstrates that overexpression of DM-lepa decreased apoptosis and stimulated cell proliferation under cold temperature.

\section{DM-lepa Over-Expression Activates the STAT3 Signal Pathway}

To gain further insight into the role of DM-lepa in facilitating proliferation and survival of ZFL cells, we focused on JAK-STAT3 pivotal signal cascades that were reported to regulate proliferation and apoptosis of cells (Takeda et al., 1998; Fernández-Riejos et al., 2008; Mattioli et al., 2009). The immunoblot analysis indicated that over-expression of leptin stimulated STAT3 expression in both normal conditions and under cold stress (Figure 6A). Using transcription of SOCS3/socs $3 a$ mRNA as a marker of the leptin stimulation involved in the JAK2/STAT3 pathway, the qPCR analysis confirmed significant upregulation of SOCS3/socs $3 a$ expression in over-expression cells (Figure 6B). We also checked the mRNA levels of related genes, $B c l-x l, B c l-2$, and $c-m y c$, which were reported to be the target genes of STATs when apoptosis was suppressed by the activation of STAT3 (Yu et al., 2009; Abad et al., 2014). The quantified expression levels indicated that overexpression of DM-lepa enhanced the expression of c-myc/myca both at normal culture temperature and under cold conditions (Figure 6C). The expression of Bcl-xl/bcl2l1 did not show much difference in normal culture temperature (data not shown), but under cold temperatures it was significantly higher in DM-lepa cells than the control (Figure 6D). Bcl2 and Bax are important members of the Bcl 2 protein family (Simchi et al., 2020) and Bax was identified as a $\mathrm{Bcl} 2$-interacting protein that opposed $\mathrm{Bcl} 2$ and promoted cell death (Oltval et al., 1993). Examination of $\mathrm{Bcl} 2 / b c l 2 a$ and Bax/baxa transcription showed that overexpression of DM-lepa significantly up-regulated the expression of the anti-apoptotic gene $\mathrm{Bcl} 2 / b c l 2 a$ (Figure 6E) while downregulating Bax/baxa (Figure 6F) expression. These data indicate that DM-lepa was associated with upregulating anti-apoptotic genes and inhibiting pro-apoptotic genes via stimulating the STAT3 signal, thus benefiting cell proliferation and survival.

\section{DM-lepa Over-Expression Decreased p53 Level by Enhancing $\mathbf{m d m} 2$ Expression in Zebrafish Liver Cells Under Cold Temperature}

To confirm the p53 signaling pathway involved in apoptosis, a p53-specific antibody was used to evaluate the levels of the 


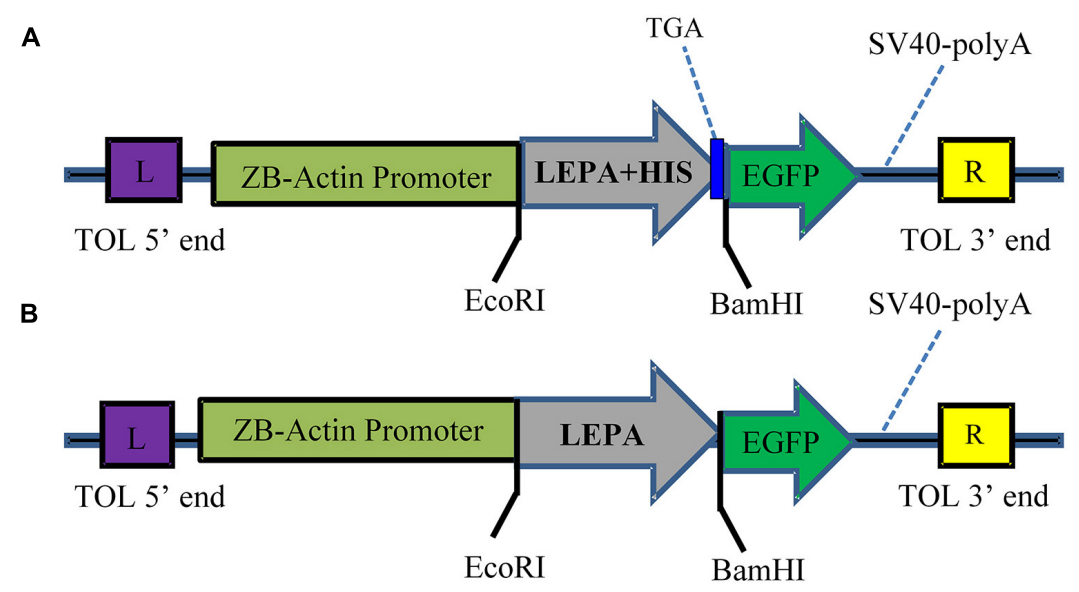

C

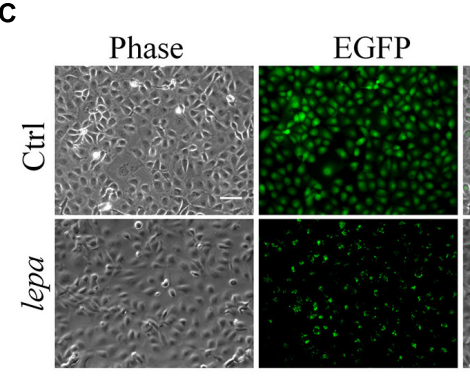

D

E
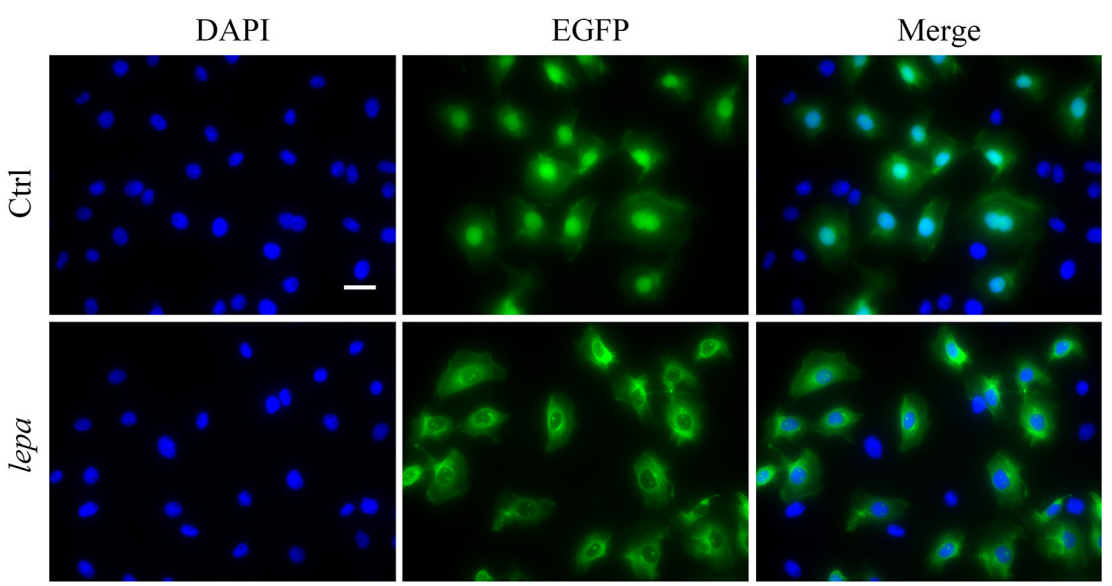

FIGURE 4 | Over-expression of DM-lepa in ZFL cells. (A,B) DM-Lepa expression vector map. (C) Fluorescence observation after transfection of ZFL cells with empty plasmid and DM-lepa gene eukaryotic expression plasmid. Scale bar, $50 \mu \mathrm{m}$. (D) Western blot analysis of DM-LEPA in ZFL. (E) Assay of subcellular localization in ZFL cells. Green fluorescence show signal of DM-LEPA and blue nuclei stained with DAPI. Scale bar, $20 \mu \mathrm{m}$.

corresponding protein in over-expression group cells. As shown in Figure 7A, over-expression of DM-lepa in ZFL cells decreased p53 levels under cold stress, which was probably negatively regulated by MDM-2, an E3 ubiquitin ligase, via a negative feedback loop that is essential to determining cell survival (Wade et al., 2013). Due to the lack of specific antibodies for zebrafish MDM-2, we checked the mRNA expression levels of MDM-2/mdm2. As seen in Figure 7B, compared with the control group, over-expression of DM-lepa significantly increased the MDM-2/mdm2 mRNA level under cold conditions.
These results accorded with leptin suppressing the activity of p53 and inhibiting p53-mediated apoptosis by upregulating MDM-2/mdm2 expression under cold temperature.

\section{DISCUSSION}

Leptin is the primary adipogenesis inhibitor produced by mammalian adipocytes (Friedman and Halaas, 1998). It acts on the central nervous system in the brain to regulate 
A

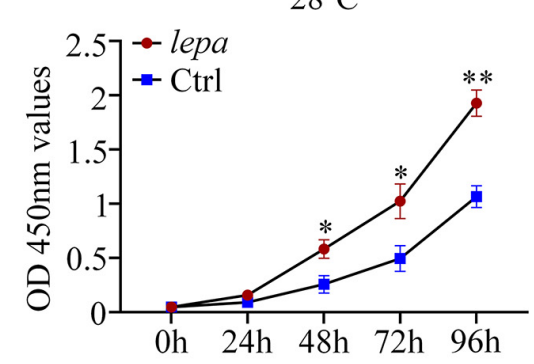

C

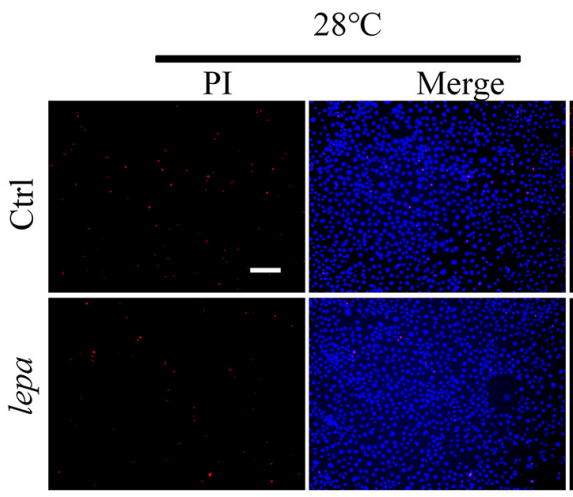

D

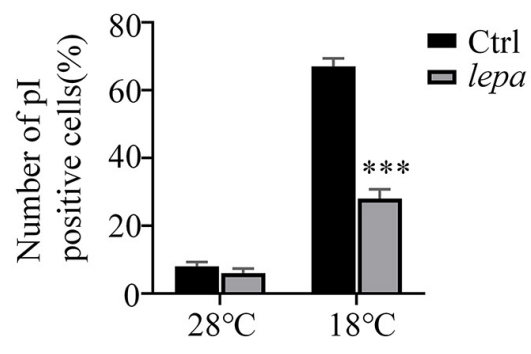

F

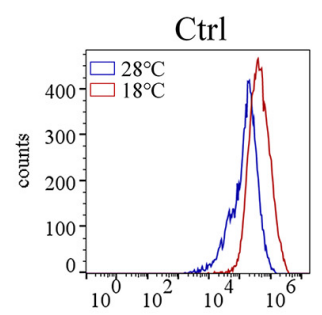

B

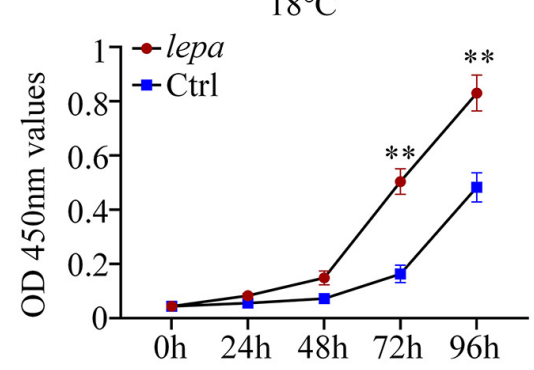

$18^{\circ} \mathrm{C}$

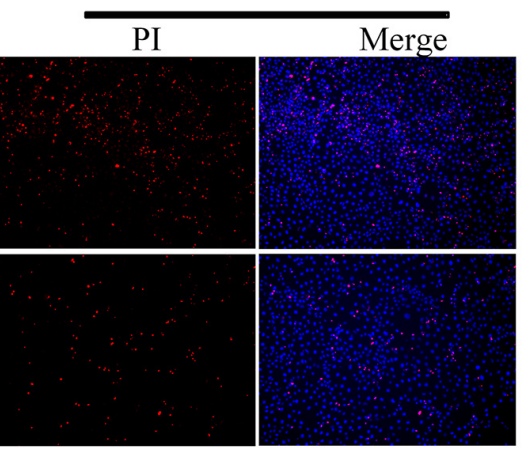

E

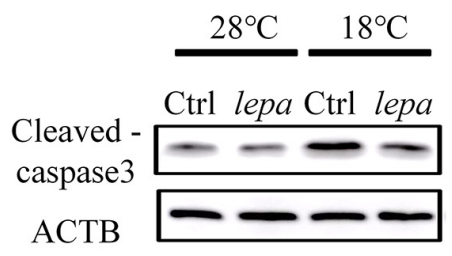

G

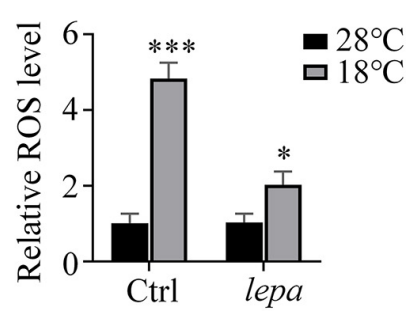

FIGURE 5 | The effect of overexpression of DM-lepa on cells. (A,B) Cell proliferation was determined by assay of CCK8. (C) Apoptosis was evaluated with Hoechst/PI staining. PI stains dead cells or late-stage apoptotic cells with a red fluorescence, and Hochest stain the nuclei with a bright-blue fluorescence. (D) The percentage of apoptotic cells was determined using ImageJ software. (E) Protein levels of cleaved-caspase 3 within cells was detected by western blot analysis. $\beta$-actin as the loading control. (F) ROS was detected by flow cytometry and analyzed using FlowJo software. (G) The relative expression of ROS Data were analyzed and graphed using GraphPad Prism 8. The results are presented as mean $\pm \operatorname{SD}(n=3),{ }^{*} P<0.05,{ }^{* *} P<0.01,{ }^{* * *} P<0.001$.

energy intake and consumption (Barb, 1999). In addition to regulating fat mass, mammalian leptin also plays a role in glucose homeostasis regulation (Morton, 2007) and reproduction
(González et al., 2000). As opposed to mammalian leptin, data on the function of ichthyic leptins are so far preliminary. In this study, we cloned and identified the leptin-a gene from 
A

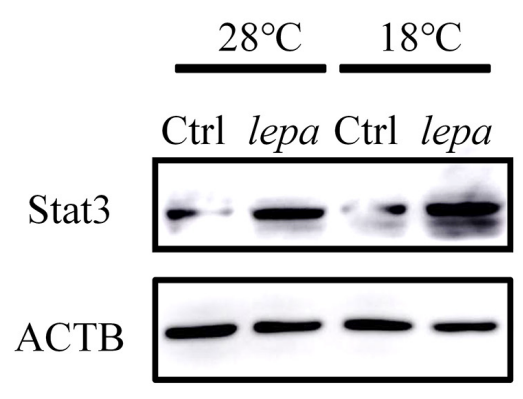

C

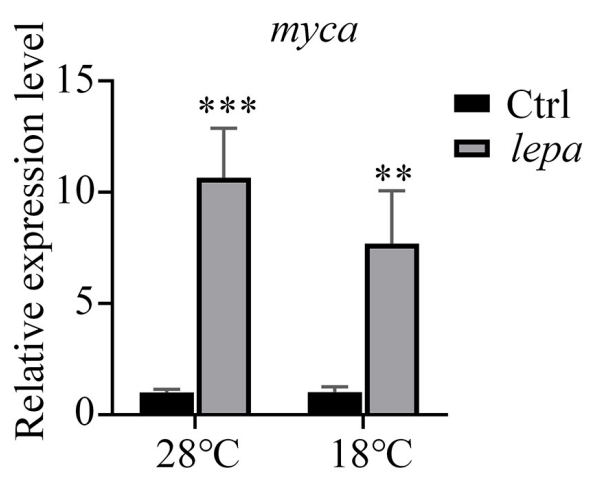

E

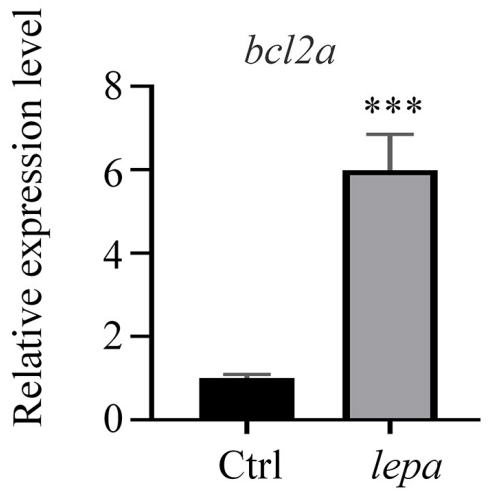

B

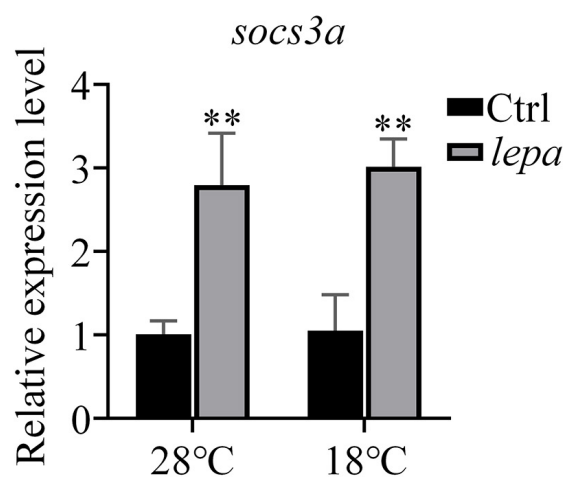

D

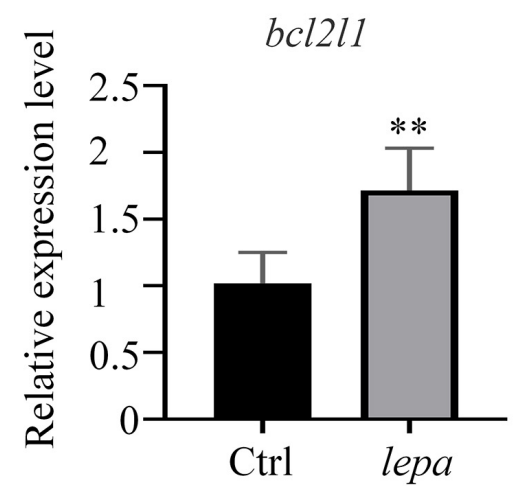

$\mathbf{F}$

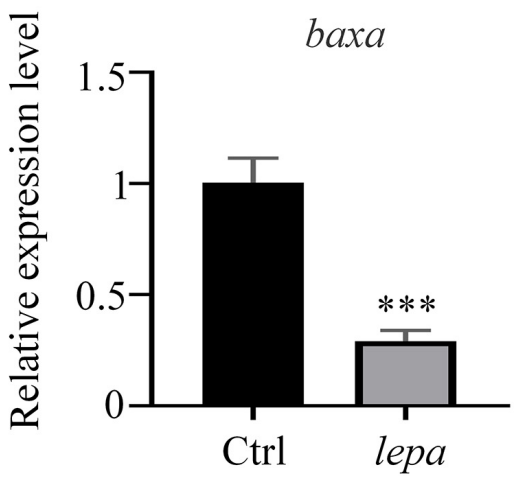

FIGURE 6 | Activation of stat3 signal pathway in DM-lepa-over-expressed cells. (A) Western blot analysis of the protein expression level of STAT3 in the cell lysates of the DM-lepa over-expression group and the control group. (B-F) A qRT-PCR assay of Socs3/socs3a, c-myc/myca, Bcl-xl/bcl211, Bcl2/bcl2a, and Baxa/baxa mRNAs in control and DM-lepa transfected cells. The results are presented as mean $\pm \mathrm{SD}(n=3),{ }^{* *} P<0.01,{ }^{* * *} P<0.001$.

D. mawsoni, a large slow-growing fish inhabiting the deep ocean at $300-2,500 \mathrm{~m}$ off the Antarctic coast where the temperature is perennially sub-zero. The amino acid sequence similarity between the DM-lepa mature peptide and lepa in other teleosts is relatively low, with only an $18.87 \%$ similarity between the DM-lepa mature peptide and zebrafish lepa, in accord with a previous study reporting that the primary structure of teleost leptin is not conserved. However, DM-lepa was predicted to contain four conserved antiparallel $\alpha$-helices, forming a 4 -helix structure consistent with mammals and most fish species. The two conserved disulfide bonds are potentially important in maintaining leptin structure and function. Mutagenic studies have reported that the disulfide bond formed by the two Cys residues is essential for leptin secretion (Keren et al., 2004). In teleosts, leptin homologs are expressed in many tissues, including the liver. For example, leptin- $a$ expression is found to be highest in the liver in many fish species, such as T. rubripes (Kurokawa et al., 2005), O. mykiss (Murashita et al., 2008), D. rerio (Gorissen et al., 2009), and O. latipes (Kurokawa and Murashita, 2009). By contrast, lepa in D. mawsoni was highest in muscle. This might relate to the extensive lipid deposits under the skin and in the musculature of $D$. mawsoni 


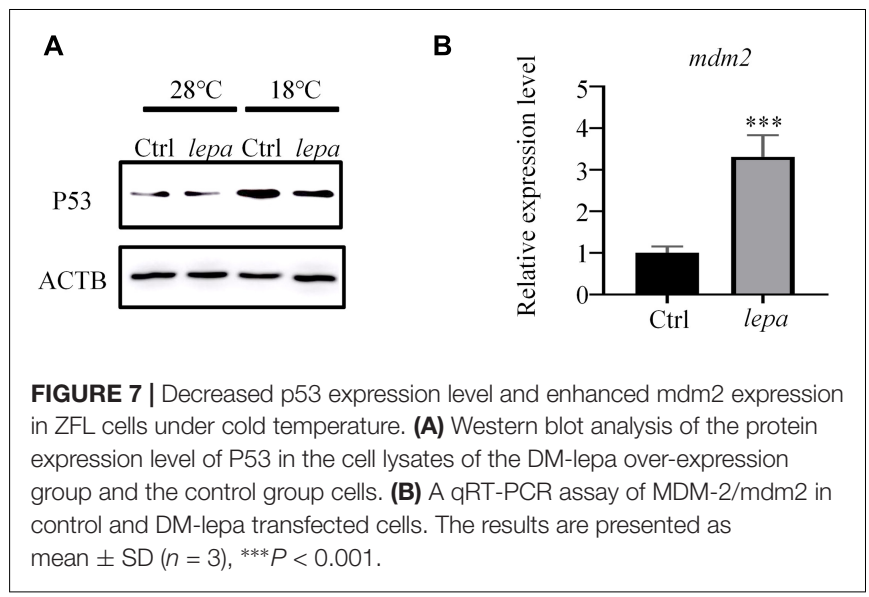

(Chen et al., 2019). Similarly in tilapia, a high expression of lepa has been reported in the subcutaneous adipose tissue (Liu et al., 2018).

Compared with lepa genes of warmer water fishes, the DM-lepa gene was subjected to positive selection with 5 positive selection sites (43N, 96K, 103F, 108T, and 142R), three of which (96K, 103F, and 108T) were localized to the 85-119 fragment; this fragment underlies the functional differences between human and non-hominoid leptins (Grasso et al., 1997, 1999; Imagawa et al., 1998), which means that the function of DM-lepa may be different from the lepa in all other comparative lineages. At the same time, our evolutionary analysis also confirmed the previous hypothesis that DM-lepa has undergone adaptive evolution, and this evolution is closely related to the cold temperature environment. Indeed, many lineages of Antarctic fishes have evolved antifreeze proteins that protect them against the threat of inoculative freezing of their hypoosmotic body fluids.

In a previous study from our laboratory, it was found that the over-expression of calmodulin from Antarctic notothenioid fish increases cold tolerance in tobacco (Yang et al., 2013). Another study showed that elevated LINE activity from an Antarctic notothenioid fish $D$. mawsoni increases the number of viable cells in cold temperatures (Chen et al., 2017). In this study, over-expression of DM-lepa significantly increased survival and proliferation in ZFL cells, when stimulated by extreme low temperature. This suggests that DM-lepa has a new function as a cell protector at cold temperature and significantly broadened our new knowledge of leptin in regulating cell fate.

It has been reported that leptin activates human peripheral blood B-cells and maintains B-cell homeostasis by inhibiting apoptosis, inducing proliferation, and prolonging survival (Lam et al., 2010; Agrawal et al., 2011). In lean mice, the addition of mouse recombinant leptin significantly increased tracheal epithelial cell proliferation (Tsuchiya et al., 1999). Both lean and obese leptin-deficient mice exhibited increased cardiac apoptosis compared with wild-type mice (McGaffin et al., 2009). Our discovery that the fish leptin has beneficial effects of survival and proliferation in the ZFL cell line is consistent with many previous findings in mammals. However, the finding of reduced ROS content in DM-lepa transfected cells in cold stress from this study is novel and implies attenuation of cold stress-induced cellular damage; the underlying mechanism is an interesting avenue for further study. Leptin modulates cell function through activation of the Janus kinase (JAK)-STAT system. The activation of STAT1 or 3 by leptin is believed to involve cell proliferation in the liver (Takahashi et al., 1997; Wang et al., 1997). Leptin's effects on cell apoptosis are likely mediated through STAT3 to increase anti-apoptotic bcl-2 and survivin gene expression and reduces caspase-3 activity (McGaffin et al., 2009). Inhibition of STAT3 signaling in tumor cells increases the apoptotic rate (Morgan and Macdonald, 2019), and loss of active STAT3 has a significant impact on both cervical cancer cell proliferation and survival (Lis et al., 2017). The downstream targets of STAT3 include factors of anti-apoptotic $(b c l-2, b c l-X L)$, pro-apoptotic (baxa) and proliferative genes (c-Myc; Kumar et al., 2016; Baek et al., 2017). Our results clearly show that DM-lepa over-expression markedly inhibited Bax/baxa expression but increased Bcl-2 expression under cold conditions, eventually resulting in an increased $\mathrm{Bcl}-2 / \mathrm{Bax}$ ratio and cell survival rate.

As the guardian of the genome, p53 is sensitive to environmental factors and is easily activated by a variety of stress signals, especially in response to temperature changes in aquatic organisms (Qian et al., 2020). Li et al. (2018) demonstrated that upregulation of p53 expression in response to low-temperature stress can cause tail malformation of the zebrafish ( $\mathrm{Li}$ et al., 2018). Qian et al. (2020) reported that genes involved in the p53 signaling pathway were largely affected in the large yellow croaker response to cold stress (Qian et al., 2020). Similarly, p53 mRNA expression was significantly up-regulated in the muscle tissue of $D$. rerio under low-temperature stress (Li et al., 2018). The accumulation of $\mathrm{p} 53$ is prevalent in fish responses to cold stress, but over-expression of p53 leads to apoptosis (Chen et al., 1996; Sharp et al., 2014; Armstrong et al., 2017). Over-expression of DM-lepa attenuated the expression of p53, suggesting reduced genotoxic stress, corresponding with a lowered ROS level. It has been reported that leptin protects human trophoblasts from serum deprivation-induced cell death by decreased expression of p53 and increased level of MDM-2 (Toro et al., 2014). We hypothesize that the cold-protection effect of DM-lepa is beneficial to Antarctic fish cells, which consistently face cold and oxidative stresses. The potential function of the leptin-a genes of other teleosts or other Antarctic fishes in coping with cold stress warrants further investigation.

\section{DATA AVAILABILITY STATEMENT}

The original contributions presented in the study are included in the article/Supplementary Material; further inquiries can be directed to the corresponding author/s.

\section{ETHICS STATEMENT}

The animal study was reviewed and approved by Shanghai Ocean University. Written informed consent was obtained from the owners for the participation of their animals in this study. 


\section{AUTHOR CONTRIBUTIONS}

YW was responsible for the experimental design and completed the data analysis and wrote the manuscript. HW and $\mathrm{LH}$ performed the experiment. LC helped perform the analysis with constructive discussions. All authors contributed to finalizing and approving the manuscript.

\section{FUNDING}

This work was supported by grants from the National Key Research and Development Program of China (2018YFD0900601), Natural Science Foundation of China

\section{REFERENCES}

Abad, C., Nobuta, H., Li, J., Kasai, A., Yong, W. H., and Waschek, J. A. (2014). Targeted STAT3 disruption in myeloid cells alters immunosuppressor cell abundance in a murine model of spontaneous medulloblastoma. J. Leukoc. Biol. 95, 357-367. doi: 10.1189/jlb.1012531

Agrawal, S., Gollapudi, S., Su, H., and Gupta, S. (2011). Leptin activates human B cells to secrete TNF- $\alpha$, IL-6, and IL-10 via JAK2/STAT3 and p38MAPK/ERK1/2 signaling pathway. J. Clin. Immunol. 31, 472-478. doi: 10.1007/s10875-0109507-1

Armstrong, L. C., Westlake, G., Snow, J. P., Cawthon, B., Armour, E., Bowman, A. B., et al. (2017). Heterozygous loss of TSC2 alters p53 signaling and human stem cell reprogramming. Hum. Mol. Genet. 26, 4629-4641. doi: 10.1093/hmg/ ddx 345

Baek, S. H., Lee, J. H., Kim, C., Ko, J.-H., Ryu, S.-H., Lee, S.-G., et al. (2017). Ginkgolic acid C 17: 1, derived from Ginkgo biloba leaves, suppresses constitutive and inducible STAT3 activation through induction of PTEN and SHP-1 tyrosine phosphatase. Molecules 22:276. doi: 10.3390/ molecules 22020276

Banerjee, K., and Resat, H. (2016). Constitutive activation of STAT 3 in breast cancer cells: a review. Int. J. Cancer 138, 2570-2578. doi: 10.1002/med.20143

Barb, C. R. (1999). The brain-pituitary-adipocyte axis: role of leptin in modulating neuroendocrine function. J. Anim. Sci. 77, 1249-1257. doi: 10.2527/1999. $7751249 \mathrm{x}$

Benner, S. A., Caraco, M. D., Thomson, J. M., and Gaucher, E. A. (2002). Planetary biology-paleontological, geological, and molecular histories of life. Science 296, 864-868. doi: 10.1126/science.1069863

Berglund, A.-C., Wallner, B., Elofsson, A., and Liberles, D. A. (2005). Tertiary windowing to detect positive diversifying selection. J. Mol. Evol. 60, 499-504. doi: 10.1007/s00239-004-0223-4

Blanquer-Rosselló, M. M., Santandreu, F. M., Oliver, J., Roca, P., and Valle, A. (2015). Leptin modulates mitochondrial function, dynamics and biogenesis in MCF-7 cells. J. Cell. Biochem. 116, 2039-2048. doi: 10.1002/jcb.25158

Chen, L., Lu, Y., Li, W., Ren, Y., Yu, M., Jiang, S., et al. (2019). The genomic basis for colonizing the freezing Southern Ocean revealed by Antarctic toothfish and Patagonian robalo genomes. Gigascience 8, 1-16. doi: 10.1093/gigascience/ giz016

Chen, S., Yu, M., Chu, X., Li, W., Yin, X., and Chen, L. (2017). Cold-induced retrotransposition of fish LINEs. J. Genet. Genomics 44, 385-394. doi: 10.1016/ j.jgg.2017.07.002

Chen, X., Ko, L. J., Jayaraman, L., and Prives, C. (1996). p53 levels, functional domains, and DNA damage determine the extent of the apoptotic response of tumor cells. Genes Dev. 10, 2438-2451. doi: 10.1101/gad.10.19.2438

Choi, Y. J., Kim, N. N., Shin, H. S., and Choi, C. Y. (2014). The expression of leptin, estrogen receptors, and vitellogenin mrnas in migrating female chum salmon, oncorhynchus keta: the effects of hypo-osmotic environmental changes. AsianAustralas. J. Anim. Sci. 27, 479-487. doi: 10.5713/ajas.2013.13592

Fernández-Riejos, P., Goberna, R., and Sánchez-Margalet, V. (2008). Leptin promotes cell survival and activates Jurkat $\mathrm{T}$ lymphocytes by stimulation of mitogen-activated protein kinase. Clin. Exp. Immunol. 151, 505-518. doi: 10. $1111 / j .1365-2249.2007 .03563 . x$
(41761134050), the Polar Innovation Platform Grant (JDXT-2019-01) and the Major Science Innovation Grant (2017-01-07-00-10-E00060) from the Shanghai Education Committee (to LC).

\section{SUPPLEMENTARY MATERIAL}

The Supplementary Material for this article can be found online at: https://www.frontiersin.org/articles/10.3389/fphys. 2021.740806/full\#supplementary-material

Supplementary Table 1 | Primers for genes involved in signal

transduction pathway.

Friedman, J. M., and Halaas, J. L. (1998). Leptin and the regulation of body weight in mammals. Nature 395, 763-770. doi: 10.1038/27376

Frøiland, E., Murashita, K., Jørgensen, E. H., and Kurokawa, T. (2010). Leptin and ghrelin in anadromous Arctic charr: cloning and change in expressions during a seasonal feeding cycle. Gen. Comp. Endocrinol. 165, 136-143. doi: 10.1016/j.ygcen.2009.06.010

Gaucher, E. A., Miyamoto, M. M., and Benner, S. A. (2003). Evolutionary, structural and biochemical evidence for a new interaction site of the leptin obesity protein. Genetics 163, 1549-1553. doi: 10.1093/genetics/163.4.1549

González, R. R., Simón, C., Caballero-Campo, P., Norman, R., Chardonnens, D., Devoto, L., et al. (2000). Leptin and reproduction. Hum. Reprod. Update 6, 290-300. doi: 10.1093/humupd/6.3.290

Gorissen, M., Bernier, N. J., Nabuurs, S. B., Flik, G., and Huising, M. O. (2009). Two different leptin paralogues in zebrafish (Danio rerio) that originate early in teleostean evolution. J. Endocrinol. 201, 329-339. doi: 10.1677/JOE-09-0034

Grasso, P., Leinung, M. C., Ingher, S. P., and Lee, D. W. (1997). In vivo effects of leptin-related synthetic peptides on body weight and food intake in female ob/ob mice: localization of leptin activity to domains between amino acid residues 106-140. Endocrinology 138, 1413-1418. doi: 10.1210/endo.138.4. 5087

Grasso, P., Leinung, M. C., and Lee, D. W. (1999). Epitope mapping of secreted mouse leptin utilizing peripherally administered synthetic peptides. Regul. Pept. 85, 93-100. doi: 10.1016/s0167-0115(99)00082-8

Hammond, J. A., Bennett, K. A., Walton, M. J., and Hall, A. J. (2005). Molecular cloning and expression of leptin in gray and harbor seal blubber, bone marrow, and lung and its potential role in marine mammal respiratory physiology. Am. J. Physiol. Integr. Comp. Physiol. 289, R545-R553. doi: 10.1152/ajpregu.00203. 2004

Hu, S., Cheng, D., Peng, D., Tan, J., Huang, Y., and Chen, C. (2019). Leptin attenuates cerebral ischemic injury in rats by modulating the mitochondrial electron transport chain via the mitochondrial STAT3 pathway. Brain Behav. 9:e01200. doi: 10.1002/brb3.1200

Huising, M. O., Geven, E. J. W., Kruiswijk, C. P., Nabuurs, S. B., Stolte, E. H., Spanings, F. A. T., et al. (2006). Increased leptin expression in common carp (Cyprinus carpio) after food intake but not after fasting or feeding to satiation. Endocrinology 147, 5786-5797. doi: 10.1210/en.2006-0824

Imagawa, K., Numata, Y., Katsuura, G., Sakaguchi, I., Morita, A., Kikuoka, S., et al. (1998). Structure-function studies of human leptin. J. Biol. Chem. 273, 35245-35249.

Kanda, N., Seno, H., Konda, Y., Marusawa, H., Kanai, M., Nakajima, T., et al. (2004). STAT3 is constitutively activated and supports cell survival in association with survivin expression in gastric cancer cells. Oncogene 23, 4921-4929. doi: 10.1038/sj.onc.1207606

Keren, B., Hadchouel, A., Saba, S., Sznajer, Y., Bonneau, D., Leheup, B., et al. (2004). PTPN11 mutations in patients with LEOPARD syndrome: a French multicentric experience. J. Med. Genet. 41:e117. doi: 10.1136/jmg.2004.021451

Konfortov, B. A., Licence, V. E., and Miller, J. R. (1999). Re-sequencing of DNA from a diverse panel of cattle reveals a high level of polymorphism in both intron and exon. Mamm. Genome 10, 1142-1145. doi: 10.1007/s003359901180

Kumar, A., Thotakura, P. L., Tiwary, B. K., and Krishna, R. (2016). Target identification in Fusobacterium nucleatum by subtractive genomics approach 
and enrichment analysis of host-pathogen protein-protein interactions. BMC Microbiol. 16:84. doi: 10.1186/s12866-016-0700-0

Kurokawa, T., and Murashita, K. (2009). Genomic characterization of multiple leptin genes and a leptin receptor gene in the Japanese medaka, Oryzias latipes. Gen. Comp. Endocrinol. 161, 229-237. doi: 10.1016/j.ygcen.2009.01.008

Kurokawa, T., Uji, S., and Suzuki, T. (2005). Identification of cDNA coding for a homologue to mammalian leptin from pufferfish, Takifugu rubripes. Peptides 26, 745-750. doi: 10.1016/j.peptides.2004.12.017

Lam, Q. L. K., Wang, S., Ko, O. K. H., Kincade, P. W., and Lu, L. (2010). Leptin signaling maintains B-cell homeostasis via induction of Bcl-2 and Cyclin D1. Proc. Natl. Acad. Sci. U. S. A. 107, 13812-13817. doi: 10.1073/pnas.1004185107

Lauth, X., Shike, H., Burns, J. C., Westerman, M. E., Ostland, V. E., Carlberg, J. M., et al. (2002). Discovery and characterization of two isoforms of moronecidin, a novel antimicrobial peptide from hybrid striped bass. J. Biol. Chem. 277, 5030-5039. doi: 10.1074/jbc.M109173200

Li, M., Miao, L., Chen, Y., Hou, H., and Chen, J. (2018). Cloning of MIPS gene in large yellow croaker (Larimichthys crocea) and the expression analysis under cold treatments. J. Agric. Biotechnol. 26, 292-301.

Lis, C., Rubner, S., Roatsch, M., Berg, A., Gilcrest, T., Fu, D., et al. (2017). Development of Erasin: a chromone-based STAT3 inhibitor which induces apoptosis in Erlotinib-resistant lung cancer cells. Sci. Rep. 7:17390. doi: 10. 1038/s41598-017-17600-X

Liu, C.-Z., He, A.-Y., Ning, L.-J., Luo, Y., Li, D.-L., Zhang, M.-L., et al. (2018). Leptin selectively regulates nutrients metabolism in Nile tilapia fed on high carbohydrate or high fat diet. Front. Endocrinol. (Lausanne) 9:574. doi: 10.3389/ fendo.2018.00574

Mattioli, B., Giordani, L., Quaranta, M. G., and Viora, M. (2009). Leptin exerts an anti-apoptotic effect on human dendritic cells via the PI3K-Akt signaling pathway. FEBS Lett. 583, 1102-1106. doi: 10.1016/j.febslet.2009.02.029

McGaffin, K. R., Zou, B., McTiernan, C. F., and O’Donnell, C. P. (2009). Leptin attenuates cardiac apoptosis after chronic ischaemic injury. Cardiovasc. Res. 83, 313-324.

Morgan, E. L., and Macdonald, A. (2019). Autocrine STAT3 activation in HPV positive cervical cancer through a virus-driven Rac1-NFKB-IL-6 signalling axis. PLoS Pathog. 15:e1007835. doi: 10.1371/journal.ppat.1007835

Morton, G. J. (2007). Hypothalamic leptin regulation of energy homeostasis and glucose metabolism. J. Physiol. 583, 437-443. doi: 10.1113/jphysiol.2007.135590

Murakami, T., and Shima, K. (1995). Cloning of rat obese cDNA and its expression in obese rats. Biochem. Biophys. Res. Commun. 209, 944-952. doi: 10.1006/bbrc. 1995.1589

Murashita, K., Uji, S., Yamamoto, T., Rønnestad, I., and Kurokawa, T. (2008). Production of recombinant leptin and its effects on food intake in rainbow trout (Oncorhynchus mykiss). Comp. Biochem. Physiol. B Biochem. Mol. Biol. 150, 377-384. doi: 10.1016/j.cbpb.2008.04.007

Oltval, Z. N., Milliman, C. L., and Korsmeyer, S. J. (1993). Bcl-2 heterodimerizes in vivo with a conserved homolog, Bax, that accelerates programed cell death. Cell 74, 609-619. doi: 10.1016/0092-8674(93)90509-o

Qian, B., Qi, X., Bai, Y., and Wu, Y. (2020). The p53 signaling pathway of the large yellow croaker (Larimichthys crocea) responds to acute cold stress: evidence via spatiotemporal expression analysis of p53, p21, MDM2, IGF-1, Gadd45, Fas, and Akt. PeerJ 8:e10532. doi: 10.7717/peerj.10532

Rønnestad, I., Nilsen, T. O., Murashita, K., Angotzi, A. R., Gamst Moen, A. G., Stefansson, S. O., et al. (2010). Leptin and leptin receptor genes in Atlantic salmon: cloning, phylogeny, tissue distribution and expression correlated to long-term feeding status. Gen. Comp. Endocrinol. 168, 55-70. doi: 10.1016/j. ygcen.2010.04.010

Sasaki, S., Clutter, A. C., and Pomp, D. (1996). Assignment of the porcine obese (leptin) gene to Chromosome 18 by linkage analysis of a new PCR-based polymorphism. Mamm. Genome 7, 471-472. doi: 10.1007/s003359900141

Sharp, A. N., Heazell, A. E. P., Baczyk, D., Dunk, C. E., Lacey, H. A., Jones, C. J. P., et al. (2014). Preeclampsia is associated with alterations in the p53-pathway in villous trophoblast. PLoS One 9:e87621. doi: 10.1371/journal.pone.0087621

Siltberg, J., and Liberles, D. A. (2002). A simple covarion-based approach to analyse nucleotide substitution rates. J. Evol. Biol. 15, 588-594. doi: 10.1046/j.14209101.2002.00416.x

Simchi, L., Panov, J., Morsy, O., Feuermann, Y., and Kaphzan, H. (2020). Novel insights into the role of UBE3A in regulating apoptosis and proliferation. J. Clin. Med. 9:1573. doi: $10.3390 / \mathrm{jcm} 9051573$
Takahashi, Y., Okimura, Y., Mizuno, I., Iida, K., Takahashi, T., Kaji, H., et al. (1997). Leptin induces mitogen-activated protein kinase-dependent proliferation of C3H10T1/2 cells. J. Biol. Chem. 272, 12897-12900. doi: 10.1074/jbc.272.20. 12897

Takeda, K., Kaisho, T., Yoshida, N., Takeda, J., Kishimoto, T., and Akira, S. (1998). Stat3 activation is responsible for IL-6-dependent T cell proliferation through preventing apoptosis: generation and characterization of T cell-specific Stat3-deficient mice. J. Immunol. 161, 4652-4660.

Tamura, K., Stecher, G., Peterson, D., Filipski, A., and Kumar, S. (2013). MEGA6: molecular evolutionary genetics analysis version 6.0. Mol. Biol. Evol. 30, 27252729. doi: $10.1093 / \mathrm{molbev} / \mathrm{mst} 197$

Toro, A. R., Maymó, J. L., Ibarbalz, F. M., Pérez, A. P., Maskin, B., Faletti, A. G., et al. (2014). Leptin is an anti-apoptotic effector in placental cells involving p53 downregulation. PLoS One 9:e99187. doi: 10.1371/journal.pone.0099187

Tsuchiya, T., Shimizu, H., Horie, T., and Mori, M. (1999). Expression of leptin receptor in lung: leptin as a growth factor. Eur. J. Pharmacol. 365, 273-279.

Wade, M., Li, Y.-C., and Wahl, G. M. (2013). MDM2, MDMX and p53 in oncogenesis and cancer therapy. Nat. Rev. Cancer 13, 83-96.

Wang, Y., Kuropatwinski, K. K., White, D. W., Hawley, T. S., Hawley, R. G., Tartaglia, L. A., et al. (1997). Leptin receptor action in hepatic cells. J. Biol. Chem. 272, 16216-16223. doi: 10.1074/jbc.272.26.16216

Yang, J., Bromage, T. G., Zhao, Q., Xu, B. H., Gao, W. L., Tian, H. F., et al. (2011). Functional evolution of leptin of Ochotona curzoniae in adaptive thermogenesis driven by cold environmental stress. PLoS One 6:e19833. doi: 10.1371/journal.pone.0019833

Yang, J., Wang, Z. L., Zhao, X. Q., Wang, D. P., Qi, D. L., Xu, B. H., et al. (2008). Natural selection and adaptive evolution of leptin in the Ochotona family driven by the cold environmental stress. PLoS One 3:e1472. doi: 10.1371/journal.pone. 0001472

Yang, N., Peng, C., Cheng, D., Huang, Q., Xu, G., Gao, F., et al. (2013). The over-expression of calmodulin from Antarctic notothenioid fish increases cold tolerance in tobacco. Gene 521, 32-37. doi: 10.1016/j.gene.2013.03.048

Yang, Z. (1997). PAML: a program package for phylogenetic analysis by maximum likelihood. Bioinformatics 13, 555-556. doi: 10.1093/bioinformatics/13.5.555

Yang, Z. (2007). PAML 4: phylogenetic analysis by maximum likelihood. Mol. Biol. Evol. 24, 1586-1591. doi: 10.1093/molbev/msm088

Yu, H., Lee, H., Herrmann, A., Buettner, R., and Jove, R. (2014). Revisiting STAT3 signalling in cancer: new and unexpected biological functions. Nat. Rev. Cancer 14, 736-746. doi: $10.1038 / \operatorname{nrc} 3818$

Yu, H., Pardoll, D., and Jove, R. (2009). STATs in cancer inflammation and immunity: a leading role for STAT3. Nat. Rev. Cancer 9, 798-809. doi: 10.1038/ $\operatorname{nrc} 2734$

Yu, L., Jin, W., Zhang, X., Wang, D., Zheng, J., Yang, G., et al. (2011). Evidence for positive selection on the leptin gene in Cetacea and Pinnipedia. PLoS One 6:e26579. doi: 10.1371/journal.pone.0026579

Yuan, L., Zhao, X., Lin, B., Rossiter, S. J., He, L., Zuo, X., et al. (2011). Adaptive evolution of Leptin in heterothermic bats. PLoS One 6:e27189. doi: 10.1371/ journal.pone.0027189

Zhang, Y., Proenca, R., Maffei, M., Barone, M., Leopold, L., and Friedman, J. M. (1994). Positional cloning of the mouse obese gene and its human homologue. Nature 372, 425-432.

Conflict of Interest: The authors declare that the research was conducted in the absence of any commercial or financial relationships that could be construed as a potential conflict of interest.

Publisher's Note: All claims expressed in this article are solely those of the authors and do not necessarily represent those of their affiliated organizations, or those of the publisher, the editors and the reviewers. Any product that may be evaluated in this article, or claim that may be made by its manufacturer, is not guaranteed or endorsed by the publisher.

Copyright (c) 2021 Wang, Wang, Hu and Chen. This is an open-access article distributed under the terms of the Creative Commons Attribution License (CC BY). The use, distribution or reproduction in other forums is permitted, provided the original author(s) and the copyright owner(s) are credited and that the original publication in this journal is cited, in accordance with accepted academic practice. No use, distribution or reproduction is permitted which does not comply with these terms. 